\title{
Clinical management of carbamazepine intoxication during anti-tubercular treatment: a case report
}

\begin{abstract}
We describe a 67-year-old man with medical history of focal post-stroke seizure and type 2 diabetes mellitus treated with carbamazepine, clobazam, gliclazide, insulin glargine, and omeprazole we visited for the onset in the last 7 days of asthenia, cough with mucus, breathing difficulty, chest pain, and weight loss. After clinical and laboratory tests, pulmonary tuberculosis was diagnosed, and a treatment with isoniazid, ethambutol, pyrazinamide rifampicin, and pyridoxine was started. Therapeutic drug monitoring of tuberculosis treatment documented that all drugs were in normal therapeutic range. Four days after the beginning of the treatment, we documented the improvement of fever, and three days later the patient showed sleepiness, visual disorder and asthenia. Clinical and pharmacological evaluation suggested a carbamazepine toxicity probably related to a drug interaction (Drug Interaction Probability Scale score $=6$ ). The impossibility to switch carbamazepine for another antiepileptic drug, due to a resistant form of seizure, induced the discontinuation of tuberculosis treatment, resulting in the normalization of serum carbamazepine levels in one day $(10 \mu \mathrm{g} / \mathrm{ml})$ and in the worsening of fever, requiring a new clinical and pharmacological evaluation. The titration dosage of carbamazepine and its therapeutic drug monitoring allowed to continue the treatment with both antitubercular drugs and carbamazepine, without the development of adverse drug reactions. To date, tuberculosis treatment was stopped and clinical evaluation, radiology and microbiology assays documented the absence of tubercular infection and no seizures appeared (carbamazepine dosage $800 \mathrm{mg}$ / bid; serum levels $9.5 \mu \mathrm{g} / \mathrm{ml}$ ).
\end{abstract}

Keywords: Carbamazepine; Isoniazid; Rifampicin; Drug-drug interactions; Therapeutic drug monitoring

Gestione clinica di una intossicazione da carbamazepina durante un trattamento antitubercolare: un caso clinico

CMI 2015; 9(2): 41-44

bttp://dx.doi.org/10.7175/cmi.v9i2.1175

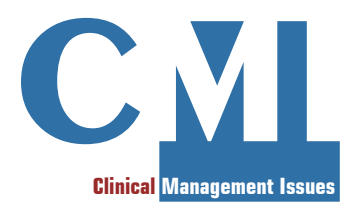

Case report
Department of Infectious Disease, ASP Lamezia Terme, Catanzaro, Italy

${ }^{2}$ Department of Health

Science, University

of Catanzaro and

Operative Unit of

Clinical Pharmacology and Pharmacovigilance, Azienda Ospedaliera

Mater Domini,

Catanzaro, Italy

3 Department of Service,

Microbiology Unit,

Central Lab, Fondazione IRCCS Cà Granda Ospedale Maggiore Policlinico, University of Milan, Italy

Corresponding author Luca Gallelli Department of

Health Science,

University of Catanzaro, Viale Europa, 88100

Catanzaro

Operative Unit of

Clinical Pharmacology and Pharmacovigilance,

Azienda Ospedaliera

Mater Domini,

Via T Campanella

115, Catanzaro, Italy

Tel. +390961712322

gallelli@unicz.it

\section{Disclosure}

The authors declare they have no competing financial interests

concerning the topics

of this article 


\begin{tabular}{|c|c|c|}
\hline Blood tests & $\begin{array}{c}\text { January } 20^{\text {th }} \text {, } \\
2014\end{array}$ & Normal range \\
\hline Glucose (mg/dl) & 89 & $70-100$ \\
\hline Creatinine clearance $(\mathrm{ml} / \mathrm{min})$ & 87 & $85-130$ \\
\hline Serum creatinine (mg/dl) & 0.75 & $0.7-1.2$ \\
\hline Potassium (mEq/) & 3.9 & $3.6-5$ \\
\hline Total cholesterol (mg/dl) & 165 & $<220$ \\
\hline LDL-cholesterol (mg/dl) & 95 & $<130$ \\
\hline HDL-cholesterol (mg/dl) & 40 & $35-39$ \\
\hline Triglycerides (mg/dl) & 72 & $50-150$ \\
\hline Aspartate aminotransferase (IU/I) & 26 & $8-48$ \\
\hline Alanine aminotransferase (IU/I) & 22 & $7-55$ \\
\hline C-reactive protein (mg/l) & 18 & $0.5-10$ \\
\hline Erythrocyte sedimentation rate $(\mathrm{mm} / \mathrm{h})$ & 62 & $0-22$ \\
\hline White blood cells (cells/ul) & 17,910 & $4,500-11,000$ \\
\hline
\end{tabular}

Table I. Laboratory findings at admission

larly during the treatment with drugs that have a narrow therapeutic index.

\section{CASE REPORT}

A 67 -year-old man (weight $=65 \mathrm{~kg}$, height $=1.68 \mathrm{~m}$ ) was referred for evaluation on January the $20^{\text {th }}, 2014$ owing to the onset in the last 7 days of asthenia, cough with mucus, breathing difficulty, chest pain, and weight loss $(1.8 \mathrm{~kg})$. His medical history reported focal post-stroke seizure unresponsive to several antiepileptic drugs (i.e., oxcarbazepine, topiramate, levetiracetam, lamotrigine, valproic acid) and well-controlled type 2 diabetes mellitus ( $\mathrm{HbA} 1 \mathrm{c}<7 \%)$.

Medications included carbamazepine (800 mg/bid), clobazam (100 mg/daily), gliclazide $(30 \mathrm{mg} / \mathrm{tid})$, insulin glargine $(100$ $\mathrm{IU})$, and omeprazole $(20 \mathrm{mg} /$ daily). On physical examination, blood pressure was $108 / 70 \mathrm{mmHg}$, heart rate $=83$ beats $/ \mathrm{min}$, respiratory rate $=20$ breaths $/ \mathrm{min}$, temperature $=38.1^{\circ} \mathrm{C}, \mathrm{SpO}_{2}=98 \%$ on room air; tuberculin skin test was performed.

Laboratory test revealed high levels of Creactive protein $(\mathrm{CRP}=18 \mathrm{mg} / \mathrm{l})$, erythrocyte sedimentation rate $(\mathrm{ESR}=62 \mathrm{~mm} / \mathrm{h})$ and white blood cells (WBC $=17,910$ cells $/$ $\mu 1)$. Other biochemical tests were in normal range (Table I).

Chest X-ray showed multifocal opacities in the right upper lobe with thickening and upward shift of the minor fissure, pleural effusion, and hilar lymphadenopathy. Three days later, tuberculin skin test proved positive, as confirmed by interferon-gamma release blood test, while microbiology of sputum documented the presence of Mycobacterium tuberculosis. Pulmonary tuberculosis was diagnosed and a treatment with a fixed-dose combination of isoniazid $75 \mathrm{mg} /$ day, ethambutol $275 \mathrm{mg} /$ day, pyrazinamide $400 \mathrm{mg} /$ day and rifampicin $150 \mathrm{mg} /$ day $\left(\operatorname{Rimstar}^{\circledR}\right)+$ pyridoxine ( $50 \mathrm{mg} /$ day) was started. Two days later, the TDM of tuberculosis treatment, performed 2 hours after drug administration, documented that all drugs were in normal therapeutic range: isoniazid $=4.6 \mu \mathrm{g} / \mathrm{ml}$ (normal range $=3-6 \mu \mathrm{g} / \mathrm{ml}) ;$ ethambutol $=4 \mu \mathrm{g} /$ $\mathrm{ml}$ (normal range $=2-6 \mu \mathrm{g} / \mathrm{ml}) ;$ pyrazinamide $=32.8 \mu \mathrm{g} / \mathrm{ml}$ (normal range $=20-50$ $\mu \mathrm{g} / \mathrm{ml}$ ); rifampicin $=8.5 \mu \mathrm{g} / \mathrm{ml}$ (normal range $=8-24 \mu \mathrm{g} / \mathrm{ml}$ ). Four days after the beginning of drug treatment, we documented the improvement of fever $\left(36.8^{\circ} \mathrm{C}\right)$ but, three days later, the patient showed sleepiness, visual disorders, and asthenia. On physical examination, he was conscious and oriented in both time and space and presented somnolence, ataxia, and nystagmus; blood pressure was $97 / 68 \mathrm{mmHg}$ with a pulse heart rate $=96$ beats/min; electrocardiography revealed a cardiac block. Other causes of conscious disorders e.g. trauma, substance abuse, and infections were ruled out. Laboratory analysis and abdominal ultrasound examinations were negative; renal, liver, and heart failures were ruled out. Carbamazepine intoxication was postulated, and TDM confirmed it (serum carbamazepine levels $=16.60 \mu \mathrm{g} / \mathrm{ml}$; normal range $=6-12 \mu \mathrm{g} / \mathrm{ml})$. Pharmacological evaluation suggested a possible DDI between tuberculosis treatment and carbamazepine (Drug Interaction Probability Scale score $=6$ ).

The impossibility to switch from carbamazepine to another antiepileptic drug, due to a resistant form of seizure, induced the discontinuation of tuberculosis treatment, resulting in the normalization of serum carbamazepine levels in one day $(10 \mu \mathrm{g} / \mathrm{ml})$. Two days later, we recorded a worsening of fever $\left(37.9^{\circ} \mathrm{C}\right)$ that required a new clinical and pharmacological evaluation. Considering history, co-morbidity and drug treatment, tuberculosis treatment was re-administered and carbamazepine was titrated in 3 administrations $/$ day (total $=400 \mathrm{mg} /$ day), resulting in a good control of clinical symptoms. TDM of carbamazepine performed one day later was in normal range $(10.1 \mu \mathrm{g} / \mathrm{ml})$.

One- and two-month follow-up revealed a good control of tubercular disease, while 


\begin{tabular}{|c|c|c|}
\hline Time & Symptoms/lahoratory tests & Treatment \\
\hline $\begin{array}{l}\text { Admission } \\
\text { January } 20^{\text {th }}, 2014\end{array}$ & $\begin{array}{l}\text { Asthenia, cough with mucus, breathing difficulty, chest pain and } \\
\text { weight loss }\end{array}$ & Carbamazepine $(1,600$ mg/day $)$ \\
\hline January 23 ${ }^{\text {rd }}, 2014$ & Diagnosis of tuberculosis & Start Rimstar ${ }^{\circledR}+$ pyridoxine \\
\hline January $25^{\text {th }}, 2014$ & TDM of tuberculosis treatment: normal range & \\
\hline January 29th, 2014 & Improvement of fever & \\
\hline February $1^{\text {st }}, 2014$ & $\begin{array}{l}\text { Sleepiness, visual disorder, and asthenia; blood pressure }=97 / 68 \\
\mathrm{mmHg} \text {, pulse heart rate }=96 \text { beats/min; cardiac block } \\
\text { Increase in plasma carbamazepine levels }\end{array}$ & Stop Rimstar ${ }^{\circledR}$ and pyridoxine \\
\hline February 2nd, 2014 & Normal plasma carbamazepine levels & \\
\hline February $4^{\text {th }}, 2014$ & Worsening of fever & $\begin{array}{l}\text { Start Rimstar }{ }^{\circledast}+\text { pyridoxine } \\
\text { Reduce carbamazepine (total } 400 \text { mg/day) }\end{array}$ \\
\hline February $5^{\text {th }}, 2014$ & Normal plasma carbamazepine levels & \\
\hline March, 2014 & $\begin{array}{l}\text { Normal plasma carbamazepine levels } \\
\text { No seizures } \\
\text { No adverse drug reactions }\end{array}$ & \\
\hline April, 2014 & $\begin{array}{l}\text { Normal plasma carbamazepine levels } \\
\text { No seizures } \\
\text { No adverse drug reactions }\end{array}$ & Rimstar $^{\circledR}$ switched to isoniazide + rifampicin \\
\hline October, 2014 & No tuberculosis & $\begin{array}{l}\text { Stop isoniazide + rifampicin } \\
\text { Increase carbamazepine to } \mathbf{1 , 6 0 0 ~} \mathbf{~ m g} / \text { day }\end{array}$ \\
\hline
\end{tabular}

TDM showed normal levels of both carbamazepine $(10.0 \mu \mathrm{g} / \mathrm{ml})$ and tuberculosis drugs (isoniazid $=4.7 \mu \mathrm{g} / \mathrm{ml}$; ethambutol $=14.2 \mu \mathrm{g} / \mathrm{ml}$; pyrazinamide $=34.5 \mu \mathrm{g} /$ $\mathrm{ml}$; rifampicin $=9.1 \mu \mathrm{g} / \mathrm{ml}$ ), without the development of seizure or ADRs. Tuberculosis treatment was discontinued and switched to a fixed-dose combinations of isoniazide + rifampicin. In October, tuberculosis treatment was stopped and clinical evaluation, as well as radiology and microbiology assays, documented the absence of tubercular infection. No seizure or ADRs appeared (carbamazepine dosage $=800 \mathrm{mg} / \mathrm{bid}$; serum levels $=9.5$ $\mu \mathrm{g} / \mathrm{ml})$. Time course of drug treatment during the study is reported in Table II.

\section{DISCUSSION}

Here we report the case of a 67-year-old man with type 2 diabetes mellitus and resistant epilepsy responsive to carbamazepine and clobazam. Due to the development of tuberculosis, the patient was hospitalized and treated with isoniazid, ethambutol, pyrazinamide, and rifampicin, with a good control of tuberculosis.

It has been reported that in patients with tuberculosis, diabetes contributes to increase severity [3], reducing the response to tuberculosis treatment [4]. In our patient, clinical evaluation documented an improvement of tuberculosis symptoms, while TDM revealed that tuberculosis drugs were in normal range. However, 7 days after the beginning of tuberculosis treatment, the patient lamented sleepiness, visual disorder, and asthenia. Several papers showed that the administration of isoniazid in a patient treated with carbamazepine may induce the development of liver failure $[5,6]$ able to induce conscious disorders.

Laboratory and clinical evaluation excluded secondary causes of conscious disorders (i.e. alcohol and substance abuse, encephalitis, hepatitis, neuroleptic malignant syndrome, drug toxicity).

Pharmacological evaluation hypothesized a carbamazepine intoxication related to a drug-drug interaction. In fact, carbamazepine is highly bound to plasma proteins (75$80 \%$ ), with an half-life of $12-20$ hours, and is metabolized in the liver by cytochrome P450 (CYP3A4) [7]; isoniazid and ethambutol are strong and weak CYP3A4 in-

Main questions a doctor should ask him/herself in this situation

- Have I excluded other causes able to induce symptoms?

- Can I change the treatment?

- Can I evaluate the plasma levels of each drug? 
hibitors, respectively $[8,9]$. Therefore, these drugs probably slowed the elimination of carbamazepine in our patient.

In fact, TDM documented high serum carbamazepine levels, and the discontinuation of tuberculosis treatment induced a decrease in serum carbamazepine levels, with a worsening of tuberculosis.

In agreement with our previous papers $[10,11]$, using the Drug Interaction Probability Scale (DIPS), we hypothesized an interaction between tuberculosis treatment and carbamazepine. The titration of carbamazepine dosage and its TDM allowed continuation of combined treatment with a good control both of seizure and tuberculosis and without the development of ADRs.

The Summary of Product Characteristics (SPCs) represents the primary source of information about DDIs for health care professionals. Unfortunately, DDIs cannot be listed exhaustively, consequently the information on potential DDIs may be insufficiently described, due to the limited space in the SPC.

In fact, in the present case, SPC suggests to evaluate carefully the co-administration of carbamazepine during the treatment with isoniazid, but when it is not possible to change the drugs, TDM is needed to optimize the therapeutic efficacy and safety of carbamazepine.

Keypoints

- Drug-drug interactions (DDIs) may be common during a multiple therapy

- DDIs must be considered during a differential diagnosis

- Clinical conditions as well as therapeutic drug monitoring may be important during the clinical management

\section{REFERENCES}

1. Palleria C, Di Paolo A, Giofrè C, et al. Pharmacokinetic drug-drug interaction and their implication in clinical management. J Res Med Sci 2013; 18: 601-10

2. Fiß T, Meinke-Franze C, van den Berg N, et al. Effects of a three party healthcare network on the incidence levels of drug related problems. Int J Clin Pharm 2013; 35: 763-71; http://dx.doi. org/10.1007/s11096-013-9804-x

3. Alisjahbana B, Sahiratmadja E, Nelwan EJ, et al. The effect of type 2 diabetes mellitus on the presentation and treatment response of pulmonary tuberculosis. Clin Infect Dis 2007; 45: 42835; http://dx.doi.org/10.1086/519841

4. Heysell SK, Moore JL, Keller SJ, et al. Therapeutic drug monitoring for slow response to tuberculosis treatment in a state control program, Virginia, USA. Emerg Infect Dis 2010; 16: 1546-53; http://dx.doi.org/10.3201/eid1610.100374

5. Campos-Franco J, González-Quintela A,Alende-Sixto MR. Isoniazid-induced hyperacute liver failure in a young patient receiving carbamazepine. Eur J Intern Med 2004; 15: 396-7; http:// dx.doi.org/10.1016/j.ejim.2004.07.005

6. Johannessen SI,Landmark CJ. Antiepileptic drug interactions - principles and clinical implications. Curr Neuropharmacol 2010; 8: 254-67; http://dx.doi.org/10.2174/157015910792246254

7. Bertilsson L, Tomson T. Clinical pharmacokinetics and pharmacological effects of carbamazepine and carbamazepine-10,11-epoxide. An update. Clin Pharmacokinet 1986; 11: 177-98; http:// dx.doi.org/10.2165/00003088-198611030-00001

8. Desta Z, Soukhova NV, Flockhart DA. Inhibition of cytochrome P450 (CYP450) isoforms by isoniazid: potent inhibition of CYP2C19 and CYP3A. Antimicrob Agents Chemother 2001; 45: 382-92; http://dx.doi.org/10.1128/AAC.45.2.382-392.2001

9. Lee SY, Jang H, Lee JY, et al. Inhibition of cytochrome P450 by ethambutol in human liver microsomes. Toxicol Lett 2014; 229: 33-40; http://dx.doi.org/10.1016/j.toxlet.2014.06.006

10. Gareri P, De Fazio P, Gallelli L, et al. Venlafaxine-propafenone interaction resulting in hallucinations and psychomotor agitation. Ann Pharmacother 2008; 42: 434-8; http://dx.doi. org/10.1345/aph.1K405

11. Siniscalchi A, Gallelli L, Calabrò G, et al. Phenobarbital/Lamotrigine coadministration-induced blood dyscrasia in a patient with epilepsy. Ann Pharmacother 2010; 44: 2031-4; http://dx.doi. org/10.1345/aph.1P335 